\title{
O fim do trabalho. Entre a distopia e a emancipação
} RICARDO ABR AMOVAY ${ }^{I}$

\section{Emprego e abundância}

$\mathrm{F}$ ORAM IMENSAS as diferenças de opinião e de método entre Karl Marx e John Stuart Mill. ${ }^{1}$ No entanto, para ambos, as tecnologias da revolução industrial aumentariam a tal ponto a produtividade do trabalho, que seria cada vez menor o esforço humano para satisfazer as necessidades sociais. Essa abundância permitiria, para Mill, que, no futuro, a sociedade deixasse de se organizar em torno da busca da riqueza e buscasse objetivos mais nobres (Valadão de Mattos, 1998). Em Marx o desenvolvimento das forças produtivas criaria as condições objetivas para que a produção social não se organizasse mais em torno da busca do lucro privado. Com isso a própria sociabilidade humana deixaria de ter como eixo central as trocas mercantis e assim o trabalho assalariado poderia tornar-se resquício de uma era passada (Abramovay, 2009). Claro que em ambos os casos, o pressuposto de tais utopias são transformações radicais (mesmo que, no caso de Mill, graduais) na própria organização social. Em Mill, essas transformações se exprimem no estado estacionário; em Marx, no comunismo. ${ }^{2}$

Durante o século XX esperança e desalento acompanharam algumas das mais importantes reflexões em torno da necessidade cada vez menor do trabalho para a oferta dos bens necessários à vida humana. Em 1930, John Maynard Keynes (1930) publica sua conferência sobre "As possibilidades econômicas para nossos netos", em que define o desemprego tecnológico como aquele "devido a nossas descobertas dos meios de economizar o uso do trabalho, que ultrapassam o ritmo ao qual podemos encontrar novos usos para o trabalho". Mas esse descompasso é apenas temporário. Na verdade, ele exprime o fato de que a "espécie bumana está resolvendo seu problema econômico" (grifado no original). Resolver o problema econômico significa enfrentar questões bem diferentes daquelas pelas quais é definida, convencionalmente, a própria economia como ciência, ou seja, a alocação de recursos escassos entre fins alternativos.

A semelhança com relação a John Stuart Mill e sobretudo a Marx é notável. Mas Keynes (1930) exprime preocupação ausente dos clássicos do século XIX: "pela primeira vez desde sua criação, o homem enfrenta seu real e permanente problema: como usar sua liberdade com relação à pressão dos cuidados econômicos, como ocupar o tempo livre... para viver bem, de forma sábia e agradável".

É notável também a proximidade entre o texto de Keynes e as reflexões de Hannah Arendt (1983). No prólogo de The Human Condition (publicado 
em 1958), ela comenta o lançamento do Sputnik, em 1957, como a tentativa de emancipar o homem da natureza terrestre, da quintessência de sua própria condição, daquilo que vincula o homem a "todos os outros organismos vivos" e, em última análise, aos limites naturais que definem a própria vida. A reflexão lhe serve de mote para um "acontecimento não menos ameaçador”: “a chegada da automatização que, em algumas décadas provavelmente esvaziará as fábricas e libertará a humanidade de seu fardo mais antigo e natural, o fardo do trabalho, a sujeição à necessidade" (Arendt, 1983, p.37).

Essa libertação é ilusória, já que as sociedades modernas glorificam o trabalho. E isso conduz a um decisivo paradoxo: "é uma sociedade de trabalhadores que será libertada das amarras do trabalho e esta sociedade nada sabe sobre as atividades mais altas e enriquecedoras pelas quais valeria a pena ganhar esta liberdade" (Arendt, 1983, p.37).

Em 1964, o presidente Lyndon Johnson convoca a Comissão Ad Hoc sobre a Tríplice Revolução (a cibernética, a das armas de confronto militar e a dos direitos humanos - cybernation, weaponry, human rights), que conta com um notável grupo de intelectuais, como os prêmios Nobel Gunnar Myrdal e Linus Pauling. A ênfase da Comissão é sobre a "revolução cibernética" que se encontra em seus primórdios e é um fenômeno ainda fundamentalmente norte-americano, mas que deverá, segundo a Comissão, ampliar-se mundo afora. Nessa época, o desemprego nos Estados Unidos era alto, ainda que contrabalançado pela demanda pública derivada dos gastos militares. Nesse contexto, a chamada revolução cibernética é uma ameaça, pois ela “invalida o mecanismo geral até aqui empregado para garantir os direitos das pessoas como consumidoras. ... No desenvolvimento do sistema cibernético, é potencialmente ilimitado o produto que pode ser alcançado pelos sistemas de máquinas que vão requerer escassa cooperação dos seres humanos". ${ }^{3}$

Tanto os clássicos do pensamento social acima mencionados como o relatório encomendado pelo governo Lyndon Johnson levantam questões atuais quanto ao sentido do trabalho e sua relação com o progresso técnico. No entanto, a previsão de um mundo sem trabalho nem de longe se realizou durante o século XX. Mas e agora, com a revolução digital, será que os termos do debate alteram-se qualitativamente, e o temor (ou a utopia) de um mundo em que o trabalho humano tem importância decrescente é nosso horizonte mais provável?

Não existe resposta consensual a essa pergunta, mesmo entre os especialistas do tema. Vale a pena expor o pensamento de alguns dos mais importantes estudiosos contemporâneos para que se tenha uma ideia dos termos do debate.

\section{Necessidades e desejos}

Se a produtividade amplia, por definição, o produto por trabalhador, e se a economia do século XX é marcada por fantástico aumento na produtividade, por que razão o sistema econômico contemporâneo ainda é tão dependente de trabalho? Por que razão a previsão de Keynes (Skidelsky; Skidelsky, 2012, p.23) 
de que a geração de seus netos aumentaria de quatro a oito vezes a riqueza econômica (aí sua bola de cristal funcionou razoavelmente) reduzindo-se a jornada a algo em torno de quinze horas semanais (patamar que não foi alcançado nem mesmo pelos mais avançados Estados de bem-estar social)?

Um dos mais importantes pressupostos da profecia do fim do trabalho é que, uma vez satisfeitas as necessidades em que se apoia uma vida social civilizada em termos materiais e culturais, num ambiente de avanço tecnológico, reduz-se brutalmente a quantidade de trabalho útil que a economia é capaz de absorver. No já citado texto de Keynes, ele faz uma clara distinção entre necessidades absolutas e necessidades relativas, ou seja, as "que sentimos somente se sua satisfação nos eleva acima, faz-nos sentir superiores aos outros". Luigino Bruni e Stefano Zamagni (2007) mostram que essas necessidades são satisfeitas pelo que chamam de "bens posicionais", cuja demanda tende ao infinito: uma vez alcançados, eles perdem imediatamente o valor, em virtude da propensão a que se deseje mais bens dessa natureza.

É compreensível que no século XIX e na primeira metade do século XX, os bens posicionais ocupassem um lugar pouco relevante no raciocínio dos economistas. Assim, a ideia de que uma vez satisfeitas as necessidades humanas, num contexto de elevação da produtividade a demanda por trabalho tenderia a zero torna-se verossímil. Essa ideia é, porém, contestada por ao menos duas importantes vertentes do pensamento econômico mais recente.

A primeira delas encontra-se nos trabalhos de Daron Acemoglu e seus colaboradores. Trabalho de Acemoglu em coautoria com Pascual Restrepo sustenta a ideia de que "a história da tecnologia não versa apenas sobre o deslocamento do trabalho humano por tecnologias de automação. Se assim fosse, estaríamos confinados a um estreito conjunto de velhas tarefas e trabalho com um nítido declínio da participação do trabalho na renda nacional" (Acemoglu; Restrepo, 2019a). Na verdade, o próprio avanço tecnológico acaba criando tanto novas oportunidades de consumo (borrando a distinção entre bens necessários e posicionais) como sobretudo novos produtos. Acemoglu e Restrepo mostram, por exemplo, que entre 1980 e 2015 , metade do crescimento do emprego nos Estados Unidos veio de ocupações ou tarefas não existentes antes desse período.

Isso não quer dizer, alertam os autores, que toda melhoria tecnológica tenha por consequência aumento de emprego. Tudo vai depender da capacidade de criação de novas ocupações e de quanto essas novas ocupações dependem de trabalho. Situações de lenta evolução da produtividade têm também a consequência de desacelerar a criação de novos postos de trabalho. E nos Estados Unidos, nos últimos trinta anos, apesar das inovações tão disruptivas trazidas pela revolução digital, o avanço da produtividade foi extremamente lento.

Pior: o formato da evolução tecnológica estimulou muito mais a adoção de técnicas que substituem o trabalho do que daquelas que o tornam mais produtivo. A automação tornou-se barata (inclusive por meio de incentivos gover- 
namentais), e desestimulou a adoção de técnicas que ampliem, de forma mais produtiva, o uso do trabalho. Além disso, o despreparo da força de trabalho para as tarefas que exigem os conhecimentos típicos da era digital também inibiu a criação de novos postos de trabalho.

A conclusão de Acemoglu e Restrepo não consiste em fazer apologia acrítica do progresso tecnológico, como se esse, seja qual for seu conteúdo, tivesse o condão de gerar novas atividades e, portanto, multiplicar os empregos. Tudo depende do tipo de tecnologia que cada sociedade vai adotar. É nesse sentido que o importante estudo de Carl Benedict Frey (2019) distingue tecnologias que substituem daquelas que abrem caminho a (enable) trabalho.

Essa distinção é tão importante que, em paper escrito também em 2019 Acemoglu e Restrepo levantam a hipótese de a sociedade norte-americana estar adotando uma espécie equivocada de inteligência artificial: "muitas novas tecnologias - as chamadas tecnologias de automação (sublinhado no original) - não aumentam a produtividade do trabalho, mas são explicitamente voltadas a deslocar (replace) o trabalho substituindo capital barato (máquinas) num conjunto de tarefas desempenhadas por humanas" (Acemoglu; Restrepo, 2019b). A consequência é que, com essa modalidade de progresso técnico, a participação dos salários na distribuição da renda nacional vai declinando.

É completamente ilusória a ideia de que a atuação das forças de mercado conduzirá os empresários a adotar as melhores tecnologias, ou seja, as que aumentam simultaneamente a produtividade e têm incidência positiva sobre a demanda de trabalho. O alerta lançado por Acemoglu e Restrepo é tanto mais importante que eles estão entre os mais prestigiados e citados economistas do século XXI. Ao se perguntarem por que razão estão sendo adotadas as modalidades erradas de inteligência artificial, eles afirmam: "os economistas tendem a colocar grande confiança na habilidade do mercado em alocar recursos da maneira a mais eficiente. Mas a maior parte dos experts reconhece que a estrela do mercado não reluz de forma tão brilhante, quando se trata de inovação" (ibidem).

As inovações trazem externalidades e, com imensa frequência, respondem aos interesses e à cultura das empresas que dominam a vida econômica. A hipótese de Acemoglu e Restrepo é que as empresas do Vale do Silício oferecem prêmios excessivos à automação e prestam insuficiente atenção a outros usos das tecnologias de fronteira. A automação que elimina trabalho é muito menos que uma decorrência espontânea da evolução tecnológica. Ela é, isso sim, o resultado de uma opção, de um caminho que beneficia antes de tudo os gigantes que dominam o mundo digital. Há aí o que Acemoglu e Restrepo não hesitam em chamar de distorção.

A segunda vertente de contestação à ideia de que o aumento da produtividade faz que a demanda de trabalho tenda a zero vem do historiador Joel Mokir et al. (2015), num fascinante paper sobre a história da "ansiedade tecnológica" (em coautoria com Chris Vickers e Nicolas Ziebarth). Eles partem, como 
Acemoglu e Restrepo, da ideia de que a mecanização da era industrial acabou criando novas necessidades (tanto na produção como no consumo) e, com isso, novos postos de trabalho. Referindo-se ao século XIX, eles mostram que "o progresso tecnológico também assumiu a forma de inovação de produto, e criou assim setores inteiramente novos para a economia, um desenvolvimento que escapava à discussão dos economistas desta época" (Mokir et al, 2015, p.36).

Mokir e seus colaboradores não endossam a ideia de que as tecnologias digitais do século XXI são necessariamente destruidoras de empregos. Para eles as tecnologias digitais estão trazendo e vão trazer novos produtos, e com eles novas ocupações. Mas seu artigo já adianta duas tendências claras e preocupantes. A primeira é a diferenciação social nas oportunidades de emprego, na própria remuneração dos trabalhadores e na maneira como usam o tempo livre. Trabalhadores que não completaram a high school (correspondente a nosso ensino médio), nos Estados Unidos, tiveram ampliado seu tempo de lazer entre 1965 e $2003 \mathrm{em} \mathrm{dez} \mathrm{horas} \mathrm{semanais,} \mathrm{tempo} \mathrm{que} \mathrm{passou} \mathrm{a} \mathrm{ser} \mathrm{dedicado} \mathrm{basicamente} \mathrm{à}$ televisão. Já entre os diplomados do curso superior esse aumento no tempo de lazer foi de apenas uma hora. A mecanização vem atingindo tarefas rotineiras, justamente as executadas por quem se encontra na base da pirâmide.

A segunda tendência apontada por Mokir e seus colaboradores é a maior flexibilidade do trabalho e, com ela, maior incerteza para os trabalhadores. Quase metade dos trabalhadores em tempo parcial nos Estados Unidos tem conhecimento de seu calendário de trabalho com menos de uma semana de antecedência. Kalil Filho (2019) mostrou os impactos destrutivos do poder das empresas-plataforma como Uber ou Amazon Turk sobre a vida cotidiana dos trabalhadores. O que Mokir e seus colaboradores antecipam é um mundo em que necessidades básicas serão quase que universalmente preenchidas, mas onde provavelmente os segmentos que se encontram na base da pirâmide social terão que ser objeto de transferências públicas para não cair na miséria absoluta.

Os trabalhos de Acemoglu e Restrepo, bem como os de Mokir e seus colaboradores são expressivos de uma vertente do pensamento econômico contemporâneo que recusa frontalmente a ideia de que a revolução digital significa o fim do trabalho. Mas em ambos os casos, esse otimismo é ao menos parcialmente contrabalançado pela tendência à polarização social contida no horizonte mais próximo da revolução digital. No caso de Acemoglu e Restrepo está em jogo, mais que isso, o próprio formato das tecnologias digitais atualmente predominantes.

\section{Desta vez é diferente}

A ideia de que a revolução digital trará rupturas no mercado de trabalho prejudiciais à própria coesão social pode ser sintetizada na obra de três autores de grande prestígio internacional.

O livro de Robert J. Gordon foi escolhido como um dos mais importantes de 2016 pelo Financial Times. Gordon rejeita o tratamento econômico conven- 
cional, segundo o qual a inovação sempre acaba por traduzir-se em aumento da riqueza e do bem-estar. Algumas inovações são mais impactantes que outras. Portanto, a inovação deve ser avaliada sob o ângulo de seu real efeito sobre as condições de vida. As inovações que marcaram a sociedade norte-americano no que Gordon chama de o "Século Especial" (sobretudo sua segunda metade, entre 1920 e 1970) reúne inovações que revolucionaram a vida cotidiana dos Estados Unidos tornando, quando comparados com qualquer período anterior, irreconhecíveis a forma como as pessoas se alimentavam, se vestiam, se deslocavam, se comunicavam, bem como a carga do trabalho tanto para o mercado como dentro dos domicílios.

Foi nesse período que se alcançou o acesso aos bens e serviços que permitiram que, entre 1870 e 1970, a expectativa de vida média norte-americana passasse de 45 para 72 anos. Na raiz dessas transformações revolucionárias encontram-se as cinco grandes redes que romperam com o isolamento do domicílio tradicional: a eletricidade, a água encanada, o saneamento básico, o telefone, o rádio (e, posteriormente, a televisão). Além dessas, a generalização do acesso ao motor a explosão interna e a substituição do cavalo pela força mecânica não só permitem melhorar a higiene das cidades, como, sobretudo, ampliam de forma inédita a mobilidade das pessoas dando lugar à instalação da classe média na periferia das grandes aglomerações urbanas. Por fim, a descoberta dos antibióticos e dos mais importantes tratamentos contra o câncer completa um quadro social em que os ganhos de produtividade eram paralelos a conquistas massivas nas condições de vida e de trabalho.

Essas inovações não exigiam dos trabalhadores conhecimentos e habilidades que estivessem acima daquilo que os sistemas de educação e formação profissional ofereciam. Elas eram neutras, sob o ângulo das habilidades exigidas dos trabalhadores, para sua integração ao mercado de trabalho. Essa neutralidade é uma das razões da redução das desigualdades nos países desenvolvidos entre o final da crise de 1929 e o início dos anos 1970. As inovações concentravam-se naquilo que determinava melhoria nos padrões de vida e as técnicas para a oferta desses bens e desses serviços eram exigentes em conhecimentos que estavam à altura das habilidades dos trabalhares. $\mathrm{O}$ resultado é que os lucros cresciam numa tendência praticamente paralela ao crescimento dos salários, o que contribuiu decisivamente para a redução da desigualdade de renda.

O grande problema das inovações que marcam a revolução digital é que elas são enviesadas (biased skill), ou seja, exigem dos trabalhadores habilidades para as quais apenas a minoria entre eles está verdadeiramente preparada. Daí a forte propensão a uma espécie de dualização do mercado de trabalho, dividido entre os poucos que exercem atividades criativas e bem remuneradas e a massa que beira permanentemente a irrelevância.

A crescente irrelevância do trabalho nos países desenvolvidos é também o tema do livro que recebeu em 2016 o prêmio de melhor livro de negócios do 
ano, atribuído pela McKinsey e pelo Financial Times. Seu autor, Martin Ford, não tem dúvida: desta vez é diferente. A ascensão dos robôs (título de seu livro) dá lugar à radical e inédita dissociação entre o aumento da riqueza e os ganhos sociais a que o crescimento econômico esteve ligado desde a Revolução Industrial. De 1950 a 2010 a produtividade do trabalho nos Estados Unidos aumenta $254 \%$ e os salários (excetuando os de direção), apenas $113 \%$. O fosso entre as duas curvas começa em 1973 e não se interrompe mais. Essa distância entre salários e produtividade se torna mais grave quando se constata que a economia americana do século XXI praticamente não criou novos empregos, contrariando a tendência, desde a crise de 1929 , de aumento em $20 \%$ da ocupação assalariada a cada década. Como cerca de um milhão de pessoas entram no mercado de trabalho anualmente, a década perdida do início do século XXI significou dez milhões de empregos faltantes na economia norte-americana. Em 2013 o setor privado norte-americanos consumiu o mesmo número de horas trabalhadas que em 1998, apesar de a riqueza ter aumentado $42 \%$ e a população $40 \%$ (Ford, 2015).

Essa dissociação entre abundância e sua distribuição social está na raiz do avanço da desigualdade de renda que, nos Estados Unidos, voltou ao nível anterior ao da crise de 1929. O que está em jogo é nada menos que o próprio contrato social que envolveu a emergência das mais importantes democracias no mundo. Claro que para esse processo foi grande a influência das políticas econômicas que privilegiaram os ganhos de capital ou o aniquilamento do movimento sindical, que abrigava um terço dos trabalhadores em 1950 e hoje não reúne mais que 7\% dessa força de trabalho declinante, nos Estados Unidos.

Mas o fundamental para entender a economia do século XXI é que a ascensão dos robôs é o vetor mais importante do que Ford chama de futuro sem emprego. Desde que foi inventado, em 1958, o poder computacional do circuito integrado dobrou 27 vezes. Com isso as máquinas e os algoritmos não substituem apenas as tarefas repetitivas, mas ganham uma capacidade interpretativa que já lhes permite redigir textos e operar de forma precisa na organização de estoques ou na preparação de refeições em restaurantes de fast-food. Os fast-food estão entre os segmentos de maior expectativa quanto à criação de empregos nos Estados Unidos. E com o barateamento dos robôs e, mais que isso, com a ampliação do acesso a seus softwares, muitos dos quais estão disponíveis gratuitamente nas nuvens, sua generalização será muito mais rápida do que habitualmente se imagina. Só o McDonald's empregava, ao final da segunda década do milênio, 1,8 milhão de pessoas em 34 mil lojas ao redor do mundo.

Não é difícil vislumbrar os impactos devastadores da robotização de suas atividades, o que foi acentuado pela atual pandemia (Barret, 2020). Luxo de país desenvolvido? O maior usuário de robôs no mundo é a China, com $25 \%$ dos quase 230 mil robôs vendidos no mundo só em 2014. Aliás, um dos trabalhos citados no livro de Ford mostra que a dissociação entre os imensos ganhos na 
produtividade e a remuneração dos trabalhadores é até mais acentuada hoje na China que nos Estados Unidos.

Martin Ford é cético com relação às chances de que a educação consiga reverter essa tendência e estimule o aumento do emprego na era digital. Seu livro é importante não só pela força da demonstração e dos dados, mas também pela proposta em torno da qual, na sua opinião, se pode refazer o pacto social das sociedades contemporâneas: só a garantia de renda a todos os cidadãos, que terão cada vez mais dificuldade em buscar seus meios de vida no mercado de trabalho, poderá manter a coesão de sociedades onde a riqueza se concentra cada vez mais e a própria sobrevivência está permanentemente ameaçada.

Muito próximo ao que André Gorz (2003) havia proposto em 1988 em Metamorfoses do trabalho (mas, infelizmente, sem citá-lo), Ford preconiza um sistema de renda básica universal que se volte a melhorar a formação dos trabalhadores, a promover a alternância entre períodos de trabalho e períodos de formação e a valorização de atividades socialmente úteis, mas que o mercado não necessariamente reconhece.

O terceiro autor que exprime ceticismo quanto às possibilidades de as inovações tecnológicas atuais conduzirem à multiplicação dos empregos é Roberto Mangabeira Unger. Tanto em seu livro A economia do conhecimento (Mangabeira Unger, 2018), como no relatório que ele dirigiu para a Fundação britânica Nesta, Mangabeira Unger (2019) mostra que a economia do conhecimento, mesmo nas sociedades mais ricas e educadas, tornou-se um arquipélago de ilhas alheias ao teor principal da vida econômica que as cerca. Essa não é, porém, uma fatalidade e sim o resultado de uma escolha.

Em quase todo o mundo, as políticas de inovação voltam-se aos interesses das maiores e mais poderosas empresas. Há um abismo entre as comunidades acadêmicas e de políticas públicas que estudam e concebem mecanismos de incentivo à inovação e as voltadas à luta contra as desigualdades. É fundamental, argumentam Mangabeira Unger e seus colaboradores, que esse abismo seja suprimido. É completamente distópico conformar-se com um horizonte que considere inevitável essa concentração de riqueza e poder e proponha como compensação uma renda básica de cidadania. Democratizar a economia do conhecimento exige que se ampliem radicalmente as chances de a grande maioria da população tornar-se sujeito de seus potenciais criativos.

Combater as desigualdades não é apenas um imperativo ético em torno de valores centrais como a liberdade, a autonomia e a dignidade humana. Esse combate é também o meio mais promissor de estimular a inovação e colocar a economia do conhecimento a serviço do desenvolvimento sustentável.

\section{Conclusões}

O lugar do trabalho na coesão das sociedades contemporâneas envolve uma discussão filosófica fundamental: o que é trabalho, o que é emprego, mas, mais que isso, como podemos hoje fazer que nossa capacidade de cooperação 
resulte em vida melhor para todos e não em formas indignas e pouco valorizadas de atividades para a esmagadora maioria, ao lado de atividades criativas e edificantes para uma pequena minoria. A situação atual faz do trabalho um puro instrumento de sobrevivência, de obtenção de renda, para a grande massa da população e não só nos países em desenvolvimento. A solução para isso nos mais importantes clássicos do pensamento social (nomeadamente Keynes, Marx, mas também Stuart Mill) é a própria abolição do trabalho, resultado do próprio crescimento econômico e do aumento da produtividade.

A luta contra o aumento das desigualdades nas sociedades contemporâneas não passa pela proteção aos empregos. Seu pressuposto básico é o fortalecimento da inovação pela base da sociedade, recuperando as ambições dos criadores da internet, por uma sociedade livre, aberta e em que o avanço tecnológico sirva para melhorar a vida humana e não para tornar as pessoas irrelevantes.

\section{Notas}

1 Este artigo apoia-se na apresentação que fiz, a convite do professor Nelson Mannrich, no VIII Congresso Internacional promovido pela Academia Brasileira de Direito do Trabalho, em 2018. Agradeço as críticas do parecerista de Estudos Avançados e as sugestões de Octavio de Barros.

2 Marx, cientista que era, dedicou sua obra ao estudo do capitalismo. No entanto, a superação do capitalismo não era, para ele, uma possibilidade, e sim uma necessidade lógica decorrente das contradições inerentes à própria mercadoria, ainda que ele não tenha se aventurado na antecipação do que poderia vir a ser essa nova organização social.

3 Disponível em: <https://www.marxists.org/history/etol/newspape/isr/vol25/no03 /adhoc.html> Acesso em: 2 mar. 2021.

\section{Referências}

ABRAMOVAY, R. A economia ecológica e os desafios para os economistas de esquerda. Estudos Avançados, v.23, n.66, 2009. Disponível em: <http://www.scielo.br/scielo. php? script=sci_arttext\&pid=S0103-40142009000200009\&lng=pt\&nrm=iso\&tlng= pt>. Acesso em: 2 mar. 2021.

ACEMOGLU, D.; RESTREPO, P. Automation and New Tasks: How Technology Displaces and Reinstates Labor. Journal of Economic Perspectives, v.33, n.2, p.3-30, 2019a. Disponível em: <https://www.aeaweb.org/articles?id=10.1257/jep.33.2.3>. Acesso em: 2 mar. 2021.

. The Wrong Kind of AI? Artificial Intelligence and the Future of Labor Demand. National Bureau of Economic Research. Working Paper 25682, 2019b. Disponível em: <https://www.nber.org/papers/w25682>. Acesso em: 2 mar. 2021.

ARENDT, H. Condition de l'homme moderne. Paris: Calman-Lévy, 1983.

BARRET, B. The Future of McDonald's Is in the Deive-Thru Lane. Wired. 11 set. 2020. Disponível em: <https://www.wired.com/story/mcdonalds-drive-thru-mymc donalds-app/>. Acesso em: 2 mar. 2021. 
BRUNI, L.; ZAMAGNI, S. Civil Economy - Efficiency, Equity, Public Happiness. s. 1.: Peter Lang Publishing, 2007.

FORD, M. Rise of the Robots: Technology and the Threat of a Jobless Future. Philadelphia: Basic Books, 2015.

FREY, C. B. The Technology Trap: Capital, Labor, and Power in the Age of Automation. Princeton: Princeton University Press, 2019.

GORDON, R. The Rise and Fall of American Growth. The U. S. Standard of Living Since the Civil War. Princeton: Princeton University Press, 2016.

GORZ, A. Metamorfoses do trabalho. Crítica da Razão Econômica. São Paulo: Annablume, 2003.

KALIL FILHO, R. Capitalismo de Plataforma e Direito do Trabalbo: crowdwork e trabalho sob demanda por meio de aplicativos. São Paulo, 2019. Tese (Doutorado) Faculdade de Direito, Universidade de São Paulo. Disponível em: <https://www.teses. usp.br/teses/disponiveis/2/2138/tde-07082020-133545/pt-br.php>. Acesso em: 2 mar. 2021.

KEYNES, J. M. Economic Possibilities for our Grandchildren. In: Essays in Persuasion. New York: W. W. Norton \& Co, 1930. p.358-73. https://www.aspeninstitute. org/wp-content/uploads/files/content/upload/Intro_and_Section_I.pdf Acesso em 2 mar. 2021

MANGABEIRA UNGER, R. A economia do conbecimento. São Paulo: Autonomia Literária, 2018.

MANGABEIRA UNGER, R. et al. Imagination unleashed. Democratising the knowledge economy. Nesta, 2019. Disponível em: <https://www.nesta.org.uk/report/ imagination-unleashed/>. Acesso em: 2 mar. 2021.

MOKIR, J.; VICKERS, C.; ZIEBARTH, N. The History of Technological Anxiety and the Future of Economic Growth: Is This Time Different? Journal of Economic Perspectives, v.29, n.3, p.31-50, 2015. Disponível em: < https://pubs.aeaweb.org/doi/ pdfplus/10.1257/jep.29.3.31>. Acesso em: 2 mar. 2021.

SKIDELSKI, R.; SKIDELSKY, E. How Much Is Enough? Money and the good life. New York: Other Press, 2012.

VALADÃO DE MATTOS, L. Economia politica e mudança social: a filosofia econômica de John Stuart Mill. São Paulo: Edusp; Fapesp, 1998.

RESUMO - O fim dos empregos é anunciado como tendência incontornável ao menos desde o século XIX. A previsão e suas consequências ocuparam algumas das melhores mentes do pensamento social desde então. A revolução digital trouxe novo alento a essa profecia. Este artigo procura mostrar que, embora as formas mais avançadas da revolução digital (a Inteligência Artificial, a Aprendizagem de Máquinas e a Internet das Coisas) já estejam substituindo boa parte dos trabalhos atualmente existentes, não é aí que reside sua maior ameaça. O problema maior da revolução tecnológica do século XXI é que ela está fortalecendo uma polarização social do mercado de trabalho que vai na contramão do que foram as bases do próprio Estado de bem-estar do século XX. 
PALAVRAS-CHAVE: Trabalho, Emprego, Crescimento econômico, Automação, Polarização social, Tecnologia.

ABSTRACT - The end of jobs is heralded as an inescapable trend at least since the $19^{\text {th }}$ century. The prediction and its aftermath have occupied some of the best minds in social thinking since then. The digital revolution has given new impetus to this prophecy. This article seeks to show that, although the more advanced forms of the digital revolution (artificial intelligence, machine learning and the Internet of Things) are already replacing many of the jobs that currently exist, this is not where greatest threat lies. The biggest problem with the technological revolution of the $21^{\text {st }}$ century is that it is exacerbating the social polarization of the labor market that goes against the very foundations of the welfare state of the $20^{\text {th }}$ century.

KErWORDS: Work, Jobs, Economic growth, Automation, Social polarization, Technology.

Ricardo Abramovay é professor sênior do Programa de Pós-Graduação em Ciência Ambiental do Instituto de Energia e Ambiente da USP. @- abramov@usp.br / https://orcid.org/0000-0003-1836-5991.

Recebido em 25.2.2021 e aceito em 8.3.2021.

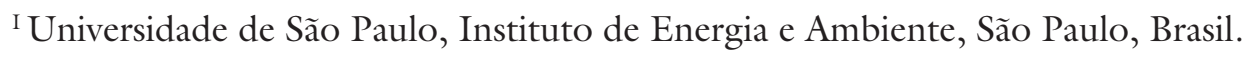

